Resenha do livro:

BINZER, Ina von. Os meus romanos: alegrias e tristezas de uma educadora alemã no

Brasil. São Paulo, Ed. Paz e Terra, 6a. ed., 1994.

Resenha por:

Marcus Fernandes Marcusso ${ }^{1}$

\title{
UM OLHAR EUROPEU SOBRE A EDUCAÇÃO E ESCRAVIDÃO NO BRASIL DO FINAL DO SÉCULO XIX: O RELATO DE INA VON BINZER.
}

O livro utilizado para a feitura desta resenha é o publicado pela editora Paz e Terra, em 1994, sendo esta a sua $6^{\circ}$ edição. A tradução foi feita por Alice Rossi e Luisita da Gama Cerqueira. A edição conta com uma apresentação de Antônio Callado e com o prefácio, da primeira edição, de autoria de Paulo Duarte.

A apresentação de Callado e o prefácio de Duarte nos oferecem um precioso guia para a realização da leitura cartas de Ina von Binzer, assinadas com seu pseudônimo Ulla von Eck, redigidas no período em que trabalhou como preceptora no Brasil, entre $1881 \mathrm{e}$ 1883. Todas as cartas foram remetidas à sua amiga alemã Grete com quem Ina demonstra ter grande intimidade, pois revela suas impressões e pensamentos mais íntimos, na maioria das vezes imbuídos da paixão característica de uma jovem de 22 anos que depara-se com uma realidade social, econômica e cultural muito diferente da Alemanha recém unificada ${ }^{2}$.

As cartas romanceadas de Ina Von Binzer são importantes fontes primárias para estudos da área de educação, e também para outras áreas como História e Teoria literária. Em alguns casos elas mesmas são o objeto do estudo ${ }^{3}$. De qualquer forma, a existência destes só reforça a importância da obra de Ina Von Binzer.

A passagem de Ina Von Binzer por nosso país pode ser resumida por sua atuação como preceptora e professora em diversas casas de famílias abastadas. A nota explicativa no começo do livro, escrita por Paulo Duarte, nos revela que alguns dos patrões de Ina detinham títulos nobiliárquicos, por conta de seus status de grandes proprietários de terras e de escravos. Segundo José Murilo de Carvalho, no livro Teatro das Sombras, a maioria dos títulos de nobreza dados aos grandes fazendeiros, que não tinham envolvimento direto com a política, era o de Barão. Ao fim do reinado de Dom Pedro II, concomitantemente a promulgação das leis abolicionistas, a concessão de títulos de nobreza adquiriu um caráter compensatório e se intensificou. (Entre 1884 e 1889 foram concedidos 238 títulos de barão) (CARVALHO, 2000: 257) O primeiro emprego de Ina Von Binzer foi em uma fazenda no interior do Rio de Janeiro, em maio de 1881, nas posses do Dr. Rameiro, com a incumbência de lecionar piano e francês aos sete filhos, num total de doze, do fazendeiro. Naturalmente, a jovem alemã relata a sua dificuldade de adaptação em todos os sentidos: desde a alimentação a pedagogia a ser utilizada com as filhas mais velhas do Dr. Rameiro, "carinhosamente" apelidadas de "Santa Inquisição". A dificuldade de adaptação agrava-se em dezembro de 1881 quando Ina é acometida de uma forte febre, sendo recomendado, por um médico, que não voltasse a fazenda do Dr. Rameiro. Ina, seguindo orientações médicas, passa alguns dias em Petrópolis, retornando ao Rio para procurar uma ocupação. Logo é contratada por um Colégio para moças que funcionava em regime de internato, com a missão de lecionar inglês, alemão e piano para as jovens provenientes da elite imperial. A passagem pela capital foi o memento mais delicado da estadia da jovem professora no Brasil. Na escola as alunas não se adaptavam aos seus métodos de ensino e cada dia de aula era descrita como cansativo e enervante. A vida no Rio de Janeiro não era 
menos penosa para Ina, o barulho e a sujeira constante das ruas e calçadas tiravam seu sono. A passagem em que Ina descreve o carnaval, que ocorre nas ruas e na escola, talvez seja a mais emblemática de sua dificuldade de adaptação. Ao procurar um dentista para extrair seu dente do siso, Ina deparasse com a festa do carnaval com suas bisnagas d'água e limões de cheiro, deixando-a em seus limites de fúria humana, além de ensopada naturalmente.

Ao consultar o cônsul alemão no Rio e queixar-se de sua condição, inclusive material, ele aconselhe-a a ir para São Paulo, onde a colônia de alemães era maior. Em março de 1882 ela relata sua chegada a São Paulo para trabalhar na casa do Dr. Costa e sua facilidade em se adaptar a cidade com os imigrantes alemães com quem inicia um bom relacionamento, especialmente, a casa dos Schaumanns onde se encontram várias nacionalidades, dando destaque ao seu futuro noiva o engenheiro inglês Mr. Hall, que representava um fabricante de máquinas inglês.

Na casa do Dr. Costa ela tem sob sua tutela, de acordo com sua denominação, uma sequência histórica: Caio, Plínio, Lavínia, Cloelia e Cornélia. Esses alunos serviram de inspiração para o título desta edição "Os meus romanos.". Apesar de feliz, sua estadia na casa do Dr. Costa é abreviada quando este envia seus filhos, Caio e Plínio, para serem educados por um padre após causarem um acidente que terminou com a morte de um cavalo dos telégrafos. $\quad$ Em julho de 1882 já escreve da fazenda São Sebastião (segundo Paulo Duarte localizada nas proximidades de Americana, interior de São Paulo) onde trabalhará para o Sr. Sousa educando suas três filhas.

Neste momento de sua estada, Ina já demonstra uma boa adaptação ao país constatada pela quase ausência de reclamações em suas cartas a Grete. Este é possivelmente a última ocupação de Ina no Brasil, pois suas cartas acabam abruptamente com uma misteriosa última carta enviada de São Paulo, em 1883, constando já no cabeçalho "Ulla von Eck George Hall, noivos" e assinada Ulla Hall.

Após essa breve apresentação da obra nos ateremos ao que o livro nos apresenta de mais rico, ou seja, seu valor enquanto fonte histórica para a discussão de questões pertencentes a época em que Ina esteve nos trópicos. Nos ateremos a duas questões principais: A questão do trabalho e a questão da educação.

O trabalho é abordado na obra sob dois aspetos, antagônicos e próximos, a escravidão e o trabalho livre. A escravidão talvez seja o único tema que perpassa praticamente todo o livro, fato explicado pelo interregno em Ina passa por aqui - 1881 a 1883 - quando a abolição já era tida como irrefreável por boa parte da classe senhorial. ${ }^{4}$

Praticamente desde a primeira carta fica evidente a curiosidade que Ina apresenta sobre a escravidão e suas preocupações diante da proximidade da abolição. São nessas cartas que ela apresenta suas principais ideias acerca do tema. Com na passagem em que questiona a total dependência dos senhores em relação ao trabalho escravo: "Neste país os pretos representam o papel principal; acho que no fundo são mais senhores do que os escravos dos brasileiros. Todo trabalho é realizado pelos pretos, toda a riqueza é adquirida por mãos dos negros."(BINZER, 1994: 40). A jovem ainda demonstra conhecimento acerca do Brasil ao citar a lei do ventre livre, de 1871, e desfazer uma confusão no pensamento dos europeus: a lei não abolia a escravidão, somente não tornava escravos os que nascessem após a sua promulgação.

Outro aspecto importante abordado por Ina, em uma conversa com o Dr. Rameiro, foi a questão dos maus tratos aos escravos, diante de uma cena de escravos fugidos de um dono violento,

Existem fazendas onde ainda se encontram as condições horríveis da Cabana do Pai Tomás? ${ }^{5}$ - perguntei 
Tão terrível assim, não será em parte alguma e talvez nunca o tenha. $\mathrm{O}$ brasileiro é mais bondoso do que o norte-americano ${ }^{6}$ e entre nós a gente preta tem condição bem diversa (BINZER, 1994: 44)

O senhor de escravos tenta mostrar a Ina sua boas ações em relação aos seus escravos - dar terras, permitir trabalho externo, batizar as crianças - chegando ambos a conclusão de que estando escravizados a tantas gerações estes não teriam capacidade intelectual de serem livres.

Posteriormente, já em São Paulo, Ina retoma as discussões acerca abolição com o Sr. Sousa e sua esposa, da qual eram partidários. Neste momento percebe-se um amadurecimento no pensamento de Ina, que agora tem uma dupla preocupação: a emancipação e a formação de uma classe operária no país. Desde sua estada no Rio de Janeiro, Ina relata a enorme falta de manufaturas e artesãos no país, destacando que os que se dedicam a esse ofício são, em sua maioria, imigrantes europeus, principalmente italianos, alemães e portugueses. Ina conclui que um bom artesão não teria dificuldade de conseguir uma boa vida no Brasil, ainda mais com a emancipação dos escravos.

Ina defende que,

Os brasileiros deviam organizar entre seu próprio povo uma classe operária que ainda não possuem, como também criar a classe dos artesãos; alcançariam esse fim com êxito, se encaminhassem as crianças pretas libertas para exercer um ofício regular (BINZER, 1994: 137).

Ainda dentro de sua proposta de "formação de uma classe operária" Ina ${ }^{7}$ toca em um aspecto fundamental relacionado com o trabalho, a instrução,

A lei de emancipação de 28 de setembro de 1871 determina entre outras coisas aos senhores de escravos que mandem ensinar a ler e a escrever a todas essas crianças. Em todo o Império, porém, não existem, talvez nem dez casas onde essa imposição seja atendida. Nas fazendas sua execução é quase impossível. (BINZER, 1994: 137)

Como pode-se observar a preocupação com a educação também ocupa um lugar de destaque no pensamento de Ina, e não só a preocupação inerente ao ofício de professora. A figura da preceptora é emblemática e central na educação brasileira do período imperial. Segundo Maria Chaves Vasconcelos a contratação de preceptoras "era uma prática comum entre os ricos do Brasil, copiada de tradicional costume da nobreza européia na educação de seus jovens fidalgos" (VASCONCELOS, 2008: 81).

Teresa Cardoso conclui o pensamento atestando que no período existia o predomínio das aulas particulares e das escolas privadas para meninas, não havendo disputa entre escolas públicas e particulares, "sequer durante o Império brasileiro se observa essa disputa, uma vez que a escola pública nunca preencheu as necessidades da população, portanto a escola particular mantinha um espaço de atuação que era complementar e não concorrente" (CARDOSO, 2004: 185),

A conclusão tirada por Ina após as tentativas de implantar/ensinar o que a elite não tinha e queria para seus filhos, ou seja, uma cópia mecanicista da cultura européia, principalmente através do ensino das línguas, é muito pertinente, "Reconheço ser indispensável adotar-se uma pedagogia aqui, mas ela deve ser brasileira e não alemã, calcada sobretudo nos moldes brasileiros e adaptada ao caráter do povo e às condições de vida doméstica" (BINZER, 1994: 87). 
Ao final parece que as questões levantadas por Ina permanecem, presentes nas discussões acadêmicas, e não acadêmicas. No final do século XX, José Murilo de Carvalho ao sintetizar o a elite política do Império brasileiro e sua relação com a realidade social em que estava inserida, "uma sociedade escravocrata governada por instituições liberais $e$ representativas; uma sociedade agrária e analfabeta dirigida por uma elite cosmopolita voltada para o modelo europeu de civilização" (CARVALHO, 2003: 417).

\section{Referências}

BINZER, Ina von. Os meus romanos: alegrias e tristezas de uma educadora alemã no Brasil. São Paulo, Ed. Paz e Terra, 6a. ed., 1994.

CARDOSO, Teresa Fachada. As aulas régias no Brasil. In: STEPHANOU, Maria; BASTOS, Maria Helena C. Histórias e memórias da educação no Brasil. Petrópolis: Vozes, 2004. V.1

CARVALHO, Jose Murilo de. A construção da ordem: a elite política imperial. Encadernado/gravado com: Teatro de sombras: a política imperial, CARVALHO, Jose Murilo de. Rio de Janeiro: Civilização Brasileira, 2003.

VASCONCELOS, Maria Celi Chaves de. Entre quatro paredes. Revista de História da Biblioteca Nacional $n^{\circ} 35$ Agosto de 2008. PP. 81-84. 3

WEFORT, Francisco Correa. As escritas de deus e as profanas: notas para uma história das idéias no Brasil Revista Brasileira de Ciências Sociais - Vol. 20 Nº. 57, 2005. pp.5-25.

\section{Notas}

${ }^{1}$ Graduado em História (UFOP) e Mestre em Educação (UFScar).

${ }^{2}$ A unificação dos estados germânicos em torno do forte estado da Prússia foi realizada em 1871, dando início ao II Império Germânico -II Reich - (1871 - 1919).

${ }^{3}$ Os estudos referidos são as seguintes dissertações: MARINO, Denise Mattos. Educação na sala de visitas: testemunhos de uma educadora alemã em São Paulo, no século XIX. Dissertação de Mestrado. Universidade Católica de Santos, 2005; RITCRAT, Marly Gonçalves Bicalho. Uma estrangeira dentro de casa: o cotidiano sob o olhar de Ina Von Binzer. Dissertação de Mestrado. Pontifícia Universidade Católica de São Paulo, 1997; RESENDE, Silvana Gomes. No avesso da cidade moderna: uma escritura feminina - Viagens ao Brasil do século XIX. Dissertação de Mestrado. UFMG, 2005; ZAITUNE, Vera Helena Rodriges. Cenas de Sala de Aula no Brasil Oitocentista: Educação em Domicílio sob a Ótica de Duas Preceptoras. Universidade São Marcos, 2004.

${ }^{4}$ Até 1883 as seguintes leis antiescravistas já haviam sido promulgadas: Em 1850 a proibição do comércio de escravos e em 1871 a Lei do ventre livre.

5 A cabana do Pai Tomás (Uncle Tom's Cabin) é um livro escrito pela norte-americana Harriet Beecher Stowe em 1852. No romance a escritora apresenta um relato em tom de denúncia acerca da questão escravista no sul do país. Sua obra teve um grande impacto na sociedade norte-americana pré-abolicionista.

${ }^{6}$ Fracisco Weffort tece um breve e conciso comentário acerca das diferenças entre a escravidão brasileira e a norte-americana, justificando o caráter virulento desta: “os brancos anglo-americanos só podiam admitir a escravidão se admitissem, ao mesmo tempo, que o negro se achava fora da humanidade. WEFORT, Francisco Correa. As escritas de deus e as profanas: notas para uma história das idéias no Brasil Revista Brasileira de Ciências Sociais - Vol. 20 N. 57, 2005. p. 18.

7 A relação estabelecida de modo natural entre instrução e trabalho apresentado por Ina indica certa influência de sua formação protestante. 